\title{
Análise da constituição do Jogo Copos das Frações sob Perspectiva da Abordagem Instrumental
}

\author{
Liliane Xavier Neves (1) \\ Universidade Estadual de Santa \\ Cruz \\ ․xneves@uesc.br
}

Rosane Leite Funato (D)

Universidade Estadual de Santa

Cruz

פrofunato@hotmail.com

Afonso Henriques (D)

Universidade Estadual de Santa

Cruz

\henry@uesc.br

\section{Analysis of the constitution of the Fractions Cups Game from the perspective of the Instrumental Approach}

\begin{abstract}
This experience report presents discussions related to the actions of a Mathematics subproject of the Institutional Program of Initiatives for Teaching on the preparation and application of a game called Fractions Glasses, developed with the objective of revisiting the notions of equivalent fractions and operations with fractions in a class of the 6th year of Elementary School. The Instrumental Approach supported the elaboration of this didactic resource and provided ways for the game, through the process of instrumental genesis, to become an effective instrument for learning the notions of fractions mentioned above. The qualitative design of the applied methodology gave support to the performance of the subjective analysis of the game constitution process, from the elaboration of a Didactic Sequence. In addition, it allowed to conclude that the revisiting of concepts of mathematical objects already worked in traditional classes, in particular, numerical fractions, by students, using games offers greater visibility and formation of a collaborative environment for the production of mathematical knowledge.
\end{abstract}

Key words: Didactic Sequence; Playful Learning; Operations with Fractions; Elementary School.

\begin{abstract}
Resumo
Este relato de experiência apresenta discussões relacionadas às ações de um subprojeto de Matemática do Programa Institucional de Bolsas de Iniciação à Docência sobre a confecção e aplicação de um jogo intitulado Copos das Frações, desenvolvido com 0 objetivo de revisitar as noções de frações equivalentes e operações com frações em uma turma do $6^{\circ}$ ano do Ensino Fundamental. A Abordagem Instrumental fundamentou a elaboração deste recurso didático e viabilizou meios para que, através do processo de gênese instrumental, o jogo se constituísse como um instrumento efetivo para a aprendizagem das noções de frações supracitados. $O$ design qualitativo da metodologia aplicada deu suporte para a realização de da análise subjetiva do processo de constituição do jogo, a partir da elaboração de uma Sequência Didática. Além disso, permitiu concluir que a revisitação de conceitos de objetos matemáticos já trabalhados em aulas tradicionais, em particular, as frações numéricas, pelos estudantes, utilizando jogos oferece maior visibilidade e formação de um ambiente colaborativo para produção do conhecimento matemático.
\end{abstract}

Palavras-chave: Sequência didática; Aprendizagem lúdica; Operações com frações; Ensino fundamental. 


\section{INTRODUÇÃO}

Todo recurso didático é um artefato que serve de suporte à prática do Professor no ensino e do aluno na aprendizagem de objetos de saberes e viabiliza a validação de propriedades, assim como a visualização de conceitos inerentes [1]. De um modo geral, os recursos didáticos se constituem instrumentos importantes no processo de ensino e aprendizagem a partir de objetivos e questionamentos advindos nas práticas educacionais. Historicamente a utilização de recursos didáticos passou a ser sinônimo de renovação pedagógica, progresso e mudança, criando expectativas quanto à prática docente. Porém, mesmo com a presença das expectativas referidas [1]. Pesquisadores [1] afirmam que a escola não faz uso efetivo desses recursos no ensino de Matemática, não considerando o seu potencial para auxiliar na discussão da aplicabilidade de conceitos ou entrosar os alunos em atividades recreativas enquanto estes aprendem, desenvolvendo esquemas de raciocínio a partir da busca de soluções [3].

Dentre os vários tipos de recursos didáticos existentes, os jogos têm características que estimulam à constituição do conhecimento matemático, ao considerar-se que ensinar Matemática é desenvolver o raciocínio lógico, estimular o pensamento independente, a criatividade e a capacidade de resolver problemas [4]. Estas ideias devem ser consideradas na formação inicial do Professor de Matemática, visto que as experiências com metodologias e utilização de diferentes recursos didáticos nesta fase de sua formação, ampliam as perspectivas que podem contribuir na potencialização da prática pedagógica desse futuro profissional. De fato, as experiências vivenciadas em sua formação é um fator importante na constituição do profissional Professor de Matemática e as reflexões sobre essas práticas viabilizam que fundamentos teóricos assumam um significado palpável na mente do licenciando, o que pode resultar de forma positiva na sua prática futura de sala de aula [5].

Nessa perspectiva, o Programa Institucional de Bolsas de Iniciação à Docência (PIBID) se constitui como um espaço de aperfeiçoamento da formação inicial do futuro Professor, viabilizando experiências com o uso de metodologias na sala de aula. O PIBID se caracteriza como uma ação que aproxima a Universidade da Escola, levando a pesquisa para a sala de aula [6], o que é significativo considerando a ação extensionista nos moldes defendidos por Freire [7], pautada na dialogicidade, na reflexão crítica de cada um sobre o ato de conhecer, na invenção e reinvenção para a transformação da realidade.

Nesse âmbito, na Universidade Estadual de Santa Cruz (UESC) o subprojeto do PIBID da área de Matemática, doravante designado PIBID-Mat, teve como proposta a elaboração de materiais didáticos em uma ação conjunta entre professores supervisores e bolsistas de iniciação científica, sob a supervisão de duas pesquisadoras, para 
posterior realização de intervenções em aulas de Matemática, a fim de implementar os materiais produzidos para revisitar conteúdos específicos da disciplina. Coordenado por duas Professoras da área de Matemática da UESC, esse subprojeto contou com a participação de vinte e quatro licenciandos em Matemática como bolsistas de Iniciação à Docência (ID) e três supervisoras, Professoras de três escolas estaduais da região sul da Bahia. A ação foi realizada em duas etapas: primeiramente foi realizado um levantamento, junto às supervisoras, dos conceitos matemáticos com os quais seus alunos apresentavam baixo rendimento. A partir dos resultados dessa investigação, na segunda etapa, cada bolsista se responsabilizou por criar/adaptar um recurso didático que auxiliasse os alunos na aprendizagem desses conteúdos, sob a orientação das coordenadoras de área e com a parceria das supervisoras. Por fim, esses materiais foram utilizados nas aulas de Matemática das supervisoras.

Dentre os objetos de estudos apontados pelos supervisores foram destacadas Adição e Subtração de frações numéricas. Os supervisores relataram que algumas das dificuldades detectadas quando ensinam frações numéricas são referentes a ideia de que a fração numérica se relaciona com um todo decomposto em partes de mesmo tamanho, quando esse todo é variável, podendo ser um objeto tangível, uma unidade de medida, um grupo de animais, entre outros. Também relataram a dificuldade de os alunos entenderem que frações diferentes podem indicar a mesma quantidade.

A iniciativa de produzir recursos didáticos e desenvolver Sequências Didáticas está atrelada à construção do conhecimento com o aluno participando do processo de aquisição do saber visado. Dessa forma, foi desenvolvido o jogo intitulado Copos com Frações para auxiliar na aprendizagem dos conceitos de Equivalência, Adição e Subtração de frações, pelos alunos de uma turma do $6^{\circ}$ ano do Ensino Fundamental de uma das escolas parceiras do subprojeto PIBID-Mat.

Para elaborar um recurso didático que fosse um instrumento para aprendizagem foi utilizada a Abordagem Instrumental [8], a qual propõe o processo de transformação de uma ferramenta em um instrumento capaz de auxiliar um sujeito na aprendizagem de um objeto de saber. Como complementação a esse processo foi constituída uma Sequência Didática (SD) que prevê o diagnostico inicial do conhecimento do aluno e uma conclusão clara do objetivo de aprendizagem, estimulando o Professor a iniciar uma ação focando-se nas dificuldades apresentadas em sala de aula pelos alunos, além de analisar métodos elaborados para facilitar a aprendizagem. Neste relato será apresentado o processo de elaboração do jogo Copos com Frações, enquanto recurso didático, além de uma breve discussão em torno da sua aplicação em sala de aula. 


\section{A CONSTITUIÇÃO DE JOGOS EDUCACIONAIS SOB A PERSPECTIVA DA ABORDAGEM INSTRUMENTAL}

A Abordagem Instrumental é uma teoria procedente da ergonomia cognitiva e, se refere a processos mentais, como percepção, atenção, cognição, controle motor, além disso, essa abordagem apresenta elementos para analisar como tais processos afetam as interações entre seres humanos e outros elementos de um sistema [9]. Sublinha-se que, essa abordagem parte do princípio de que uma ferramenta não é, automaticamente, um instrumento eficaz. Para alcançar esse status, a ferramenta deve passar por um processo chamado gênese instrumental, tornando-se significativa na aprendizagem e, assim ser chamado de instrumento. Portanto, entende-se que ferramenta é aquilo que é dado para o sujeito e, instrumento é o que é construído pelo sujeito.

As relações estabelecidas entre o sujeito, o objeto e a ferramenta durante o processo de gênese instrumental estão sistematizadas no Modelo das Situações de Atividades Instrumentais (SAI), mostrado na Figura 1 [10].

Figura 1: Modelo SAI

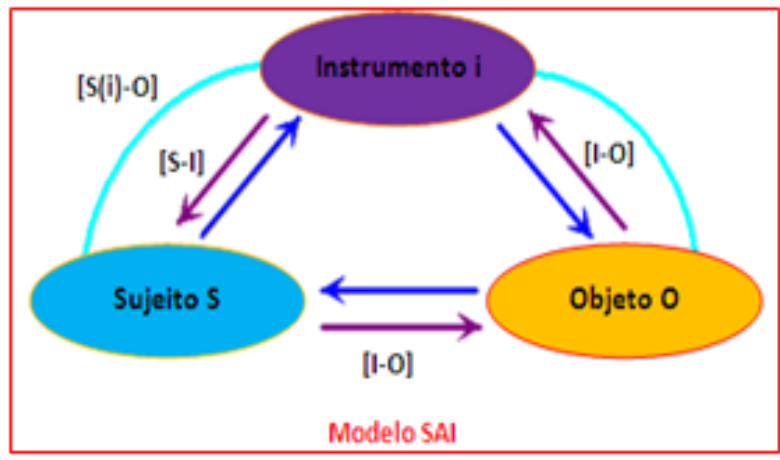

Fonte: [10]

O modelo SAI destaca as relações entre o sujeito e o objeto sobre o qual ele age, e as múltiplas interações possíveis entre os elementos do modelo nas atividades instrumentais. Para isso consideram-se, conforme mostrado na Figura 1, além da interação usual sujeito-objeto [S-O], as relações sujeito-instrumento [S-i], instrumento-objeto [iO] e a relação sujeito-objeto mediado pelo instrumento [S(i)-O]. Nas atividades propostas no subprojeto PIBID-Mat, o objeto O, é Frações Numéricas que se desdobra em Equivalência, Adição e Subtração de frações. O sujeito $\mathrm{S}$, em um primeiro momento, é o bolsista de ID, e, posteriormente, na aplicação da atividade com o instrumento, é o aluno do $6^{\circ}$ ano do Ensino Fundamental; o Instrumento i, é o jogo Copos com Frações implementado durante a realização do subprojeto aqui relatado.

A realização de tarefas de reconhecimento de Equivalência, de Adição e Subtração de frações resultou na construção de um instrumento com base no processo de gênese instrumental. Esse processo se desenvolveu sob forma de esquemas divididos 
em três categorias: esquemas de uso, referentes as atividades relativas a gestão das características e propriedades particulares do artefato; esquemas de ação instrumentada, relacionadas às atividades para as quais o artefato é um meio de realização e esquemas de atividades coletivas instrumentadas, correspondentes à utilização simultânea ou conjunta de um instrumento em um contexto de atividades compartilhadas [10].

Durante a elaboração do jogo foram realizados estudos aprofundados para a definição de suas regras com um olhar nos conceitos matemáticos visados. Foram formuladas tarefas a partir desses conceitos que revelaram as regras do jogo constituído com finalidades pedagógicas. Esse momento se refere à relação [S-i] do modelo SAI e, corresponde a mobilização de esquemas de uso e, de ação instrumentada, favorecendo a adaptação do modelo SAI (teórico) para um modelo SAI aplicado à pesquisa, tanto na sua dimensão interna, quanto externa [11], conforme mostrado na Figura 2.

Figura 2: Modelo SAI

(a) na pesquisa interna

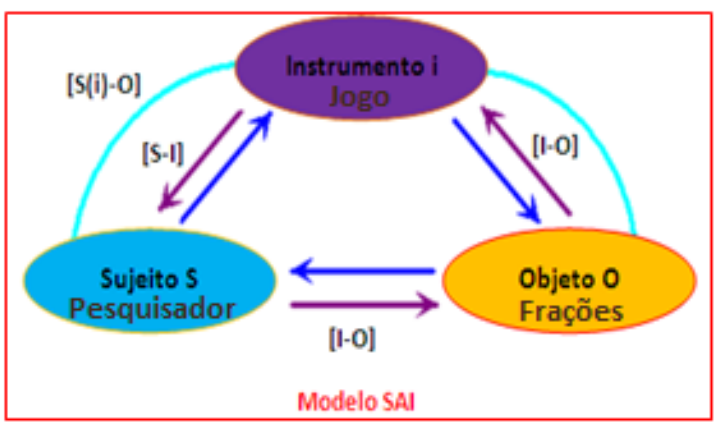

(b) na pesquisa externa

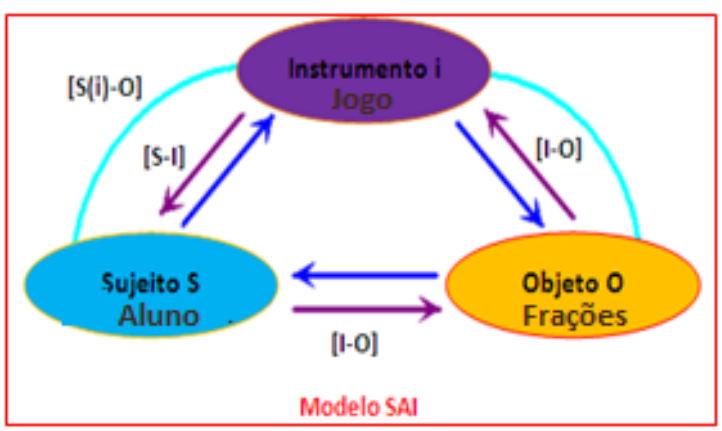

Fonte: Adaptação do Modelo SAI apresentado em [11].

São definidas duas dimensões do processo de gênese instrumental [8], a saber, instrumentação e instrumentalização. Na primeira, o sujeito constrói esquemas, procedimentos e operações para a utilização da ferramenta, referentes aos esquemas de uso, e diz respeito a relação [S-i] do modelo SAI. A segunda, refere-se à emergência das propriedades funcionais e estruturais do artefato. Ou seja, o sujeito $\mathrm{S}$ deve verificar as potencialidades e entraves do artefato, neste caso o jogo, em conformidade com o objeto de estudo (Frações numéricas) e, refere-se à [i-O] do modelo SAI. A instrumentação e instrumentalização são, portanto, determinantes nas possibilidades que o sujeito atribui ao instrumento agir sobre o objeto, construindo, assim, as propriedades funcionais que permitem essa ação na relação [S(i)-O] do modelo SAI. 


\section{METODOLOGIA PARA A CONSTITUIÇÃO DO JOGO COPOS COM FRA- ÇÕES}

Para nortear a elaboração do jogo e planejar as intervenções com os alunos em sala de aula, utilizando o artefato, mobilizou-se os aspectos metodológicos da Engenharia Didática (ED) [11, 12]. Desenvolvida por Artigue (1988), um dos aspectos da Engenharia Didática é a Sequência Didática (SD).

Uma sequência didática é um esquema experimental de situações-problema ou tarefas, realizadas com um determinado fim, desenvolvida por sessões de aplicação a partir de um estudo preliminar (análise institucional) em torno do objeto do saber e de uma análise matemática/didática, caracterizando os objetivos específicos de cada problema/tarefa ([12] (p. 122), grifo do autor).

As análises matemáticas/didáticas devem evidenciar a maneira de realização e de controle das tarefas (destacadas na praxeologia do objeto de estudo em questão, ou elaboradas com base nesta praxeologia), os resultados esperados, os pré-requisitos, as variáveis didáticas das situações e as competências necessárias para a realização das tarefas propostas. Tais variáveis possibilitam diferenciar as tarefas propostas aos alunos. Assim, amparado na engenharia [12], a Sequência Didática é decomposta em cinco etapas: (1) análise preliminar (análise institucional), (2) organização da sequência, (3) análise a priori, (4) aplicação da sequência, (5) análise a posteriori e validação.

No subprojeto do PIBID-Mat foram seguidas essas descrições, sendo que na primeira etapa realizou-se a análise institucional [12,13], após a escolha do objeto matemático de referência, notadamente a Fração numérica; a análise desse objeto em um livro didático adotado pela escola parceira e, a confecção do jogo Copos com Frações. Nas Frações numéricas mobilizadas, o numerador e o denominador, são valores numéricos inteiros conhecidos a partir da decomposição da unidade, o todo. Essa noção central permeia o capítulo sobre frações do livro adotado pela escola, o qual foi analisado na ação aqui relatada, como elemento institucional. Os detalhes da análise institucional não serão apresentados neste relatado, que tem foco na constituição do jogo Copo com Frações e na fundamentação teórica que serviu de apoio na análise do processo que configurou esse artefato como instrumento.

Na segunda etapa elaborou-se uma SD, com base na análise institucional, em torno do conteúdo Fração numérica realizada na primeira etapa utilizando Copos com Frações, enquanto artefato, visando a transformação deste em instrumento efetivo pelos alunos. Essa SD foi organizada com quatro Tarefas (Ti), com i=1, 2, 3 e 4, contendo ao menos uma subtarefa (St). Na terceira etapa realizou-se a análise matemática e didática das tarefas proposta na SD. A quarta etapa consistiu na aplicação da SD e coleta de dados construindo-se um protocolo experimental utilizado na análise a posteriori e 
validação da SD.

\subsection{Confecção do Copos com Frações enquanto artefato}

O instrumento foi elaborado para atender as dificuldades dos alunos relacionadas com à equivalência de frações e adição e subtração de frações, que são objetos do $6^{\circ}$ ano do Ensino Fundamental. Buscou-se com este material didático atender os seguintes objetivos: compreender a estrutura das frações; demonstrar os cálculos de adição e subtração de frações; analisar a equivalência entre frações e realizar simplificações de algumas frações.

O material utilizado para a confecção do Instrumento Copo com Frações foram: copos descartáveis de $300 \mathrm{ml}$, marcador permanente, água e refresco em pó na cor vermelha. Utilizando este material, cada copo foi marcado, convenientemente, com traços na superfície externa, servindo de divisórias de sua capacidade total em partes iguais ou proporcionais em relação a capacidade total do copo, conforme mostrado na Figura 3.

Figura 3: Copos com Frações

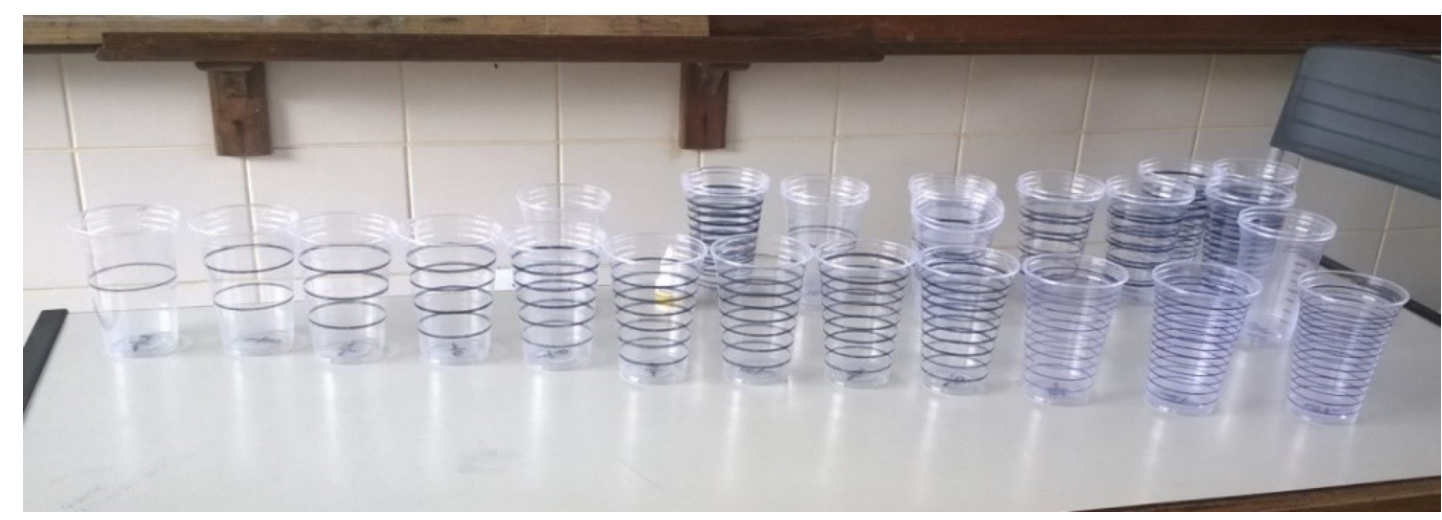

Fonte: O próprio autor.

Os traços nos copos indicam os divisores correspondentes a sua capacidade total em partes iguais, proporcionando a identificação dos valores para os denominadores das frações que foram trabalhadas, em relação a capacidade total do copo. Por exemplo, o copo marcado com dois traços pode representar 1/3 (um terço) da capacidade total do copo, 2/3 (dois terços) e 3/3 (três terços), fração que corresponde a um inteiro. Vale reforçar que a medida que foi utilizada como inteiro diz respeito a capacidade total do copo, ou seja, $300 \mathrm{ml}$. Com este instrumento confeccionado, organizou-se uma SD contendo quatro tarefas que são apresentadas a seguir.

\subsection{Sequência Didática utilizando o jogo Copos com Frações e análise à priori}

Esta sequência foi elaborada para proporcionar aos alunos do $6^{\circ}$ ano do Ensino Fundamental uma aprendizagem lúdica sobre os conceitos de comparação, equivalência, operações de adição e subtração de frações utilizando os Copos com frações. 
A primeira tarefa T1 proposta aos alunos foi formulada com o seguinte enunciado:

T1) Considerar a quantidade de líquido contida em um copo descartável de 300
ml cheio, como a unidade de medida deste copo e, representar as frações $\frac{1}{2}$ (um
meio ou meio), $\frac{1}{3}$ (um terço) e $\frac{1}{4}$ (um quarto) nos "Copos com Frações", para
responder as seguintes subtarefas:
St1 $\begin{array}{ll}\text { Observar as representações nos copos para decidir se, a fração } \frac{1}{3} \text { é maior } \\ \text { ou menor que } \frac{1}{2}, \text { justificando a resposta. } \\ \text { St2 } & \begin{array}{l}\text { Observar as representações nos copos para decidir se, a fração } \frac{1}{3} \text { é maior } \\ \text { ou menor que } \frac{1}{4}, \text { justificando a resposta. }\end{array} \\ \text { St3 } & \begin{array}{l}\text { Observar as representações nos copos para decidir se, a fração } \frac{1}{2} \text { é maior } \\ \text { ou menor que } \frac{1}{4}, \text { justificando a resposta. }\end{array}\end{array}$

Objetivo: Favorecer a utilização do instrumento na representação de frações, estimulando a capacidade dos alunos na observação e comparação de objetos envolvendo conceitos de frações, tendo como pré-requisitos, o conceito e nomenclatura de frações.

Análise Matemática: Para realizar a T1, apresenta-se a análise sequencial das três subtarefas (St1, St2 e St3). Deve-se observar, a partir da fração $\frac{1}{2}$, o numerador e o denominador, além de associar o denominador, isto é, o número 2 , a quantidade de partes que compõem a capacidade de copo, o que ocorre com o copo contendo um traço, ou duas partes da capacidade, ambas com medidas iguais. Faz-se necessário saber o que o numerador desta fração, neste caso, o número 1, representa em relação as partes (divisores) que compõem a capacidade do copo. Observando a Figura 4, infere-se que o líquido contido no copo (a) representa a fração $\frac{1}{2}$ (um meio ou meio), ou seja, a quantidade representativa da fração neste copo é a metade da sua capacidade, que é $150 \mathrm{ml}$ de água.

Observando a Figura 4, é possível notar que o copo (b) marcado com dois traços, divide a capacidade deste em três partes, sendo uma destas partes ocupada pelo líquido representando $\frac{1}{3}$ (um terço) da sua capacidade. Ou seja, copo (b) contém apenas a terça parte de $300 \mathrm{ml}$, ou equivalentemente, $100 \mathrm{ml}$ de água. Por fim, como mostrado na Figura 4, o copo (c) é marcado com três traços divisórios, tendo quatro partes e uma destas é ocupada pelo líquido, representando $\frac{1}{4}$ (um quarto) da capacidade do copo, o que significa que nele há apenas a quarta parte da capacidade, que seja 75 $\mathrm{ml}$ de água. Conjectura-se, portanto, que a quantidade de água depositada em cada copo corresponde com o resultado da divisão do valor inteiro $(300 \mathrm{ml})$ pelo valor do denominador da fração desejada. 
Figura 4: Comparação de frações.

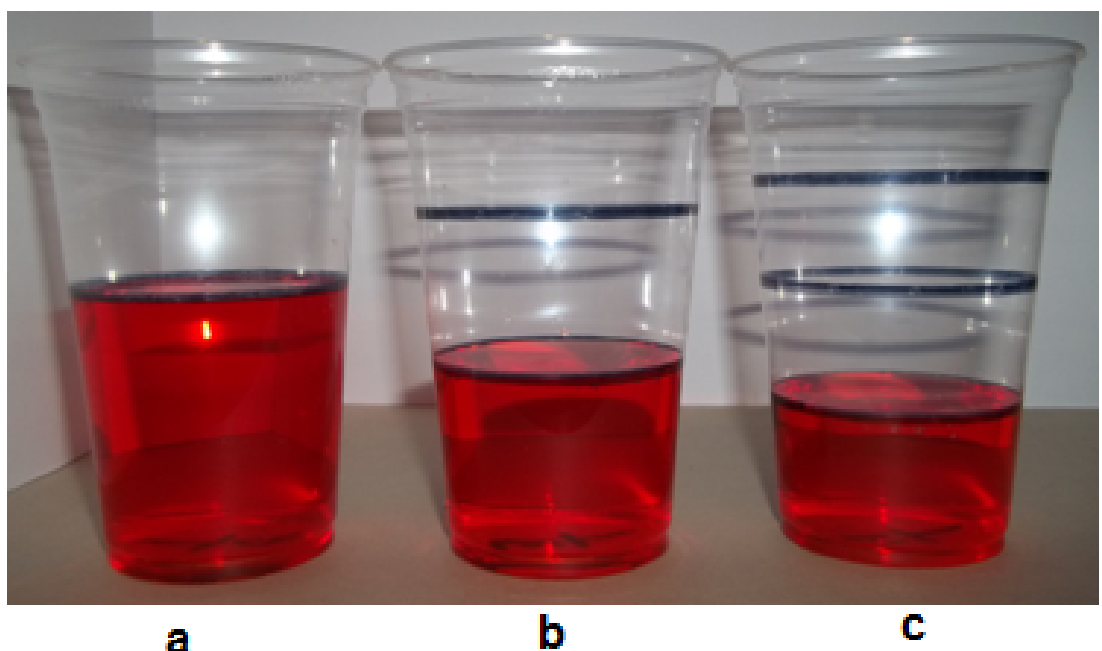

Fonte: O próprio autor.

Na Figura 4 mostra-se a diferença entre a quantidade de água colorida contida em cada copo, assim como os traços que representam as partições do copo. Em cada copo foi representada uma fração diferenciada da outra pela quantidade de líquido e do nível do traço no copo. Considerando as representações das frações $\frac{1}{2}, \frac{1}{3}$ e $\frac{1}{4}$ nos copos, o aluno analisa se a fração $\frac{1}{2}$ é maior do que $\frac{1}{3}$ e se esta é maior do que $\frac{1}{4}$. Evidencia-se nesse processo a gênese instrumental na utilização do Copos com Frações tornando-se um instrumento para o aluno na resolução de situações com frações. Esperando-se então a comparação $\frac{1}{2}>\frac{1}{3}>\frac{1}{4}$.

Essa análise viabiliza a superação das dificuldades dos alunos relativas à comparação de frações, pois a manipulação dos objetos concretos pelos alunos e, o seu envolvimento deles com análise de situações, pode mobilizar a compreensão das relações de comparação. Tendo-se a Fração como objeto matemático de referência, nota-se que uma parte tomada de duas partes do inteiro é maior que uma parte tomada de três partes do mesmo inteiro, embora o número três seja maior do que o número dois.

A segunda tarefa T2 que compõe a SD foi apresenta com o seguinte enunciado.

\begin{tabular}{|c|c|}
\hline \multicolumn{2}{|r|}{$\begin{array}{l}\text { T2) Utilizar os Copos com frações e a água colorida para realizar as seguintes } \\
\text { subtarefas. }\end{array}$} \\
\hline St1 & $\begin{array}{l}\text { Considerar as frações } \frac{1}{2}, \frac{2}{4}, \frac{3}{6} \mathrm{e} \text {, representar cada uma em um Copo com } \\
\text { frações utilizando a água colorida. }\end{array}$ \\
\hline St2 & $\begin{array}{l}\text { Comparar essas frações por observação, a partir da representação } \\
\text { fornecida em St1. }\end{array}$ \\
\hline t3 & Explicar por escrito, justificando a equivalência entre essas frações. \\
\hline
\end{tabular}

Objetivo: Desenvolver a noção de frações equivalentes utilizando o jogo Copos com Frações, sendo pré-requisitos os conceitos de fração e de equivalência de frações. 
Análise Matemática: Para realizar a tarefa T2 considerou-se quatro Copos com frações. Conforme mostrado na Figura 5, para cumprir a St1, o líquido colorido foi colocado em um copo com duas frações, isto é, com um traço, que marca a divisão da capacidade total em duas partes, representando assim a fração $\frac{1}{2}$ (cf. Figura $5 a$ ). Em seguida, conforme mostrado na Figura $5 b$, colocou-se em um copo com três traços que marcam a divisão da capacidade total em quatro partes, o líquido colorido até o segundo traço, representando assim a fração $\frac{2}{4}$. O terceiro (cf. Figura $5 \mathrm{c}$ ) é uma repetição do primeiro, equivalente ao segundo. Por fim, colocou-se em um copo com cinco traços que marcam a divisão da capacidade total em seis partes, o líquido colorido até o terceiro traço, representando assim a fração $\frac{3}{6}$ (cf. Figura 5 d).

Figura 5: Frações equivalentes
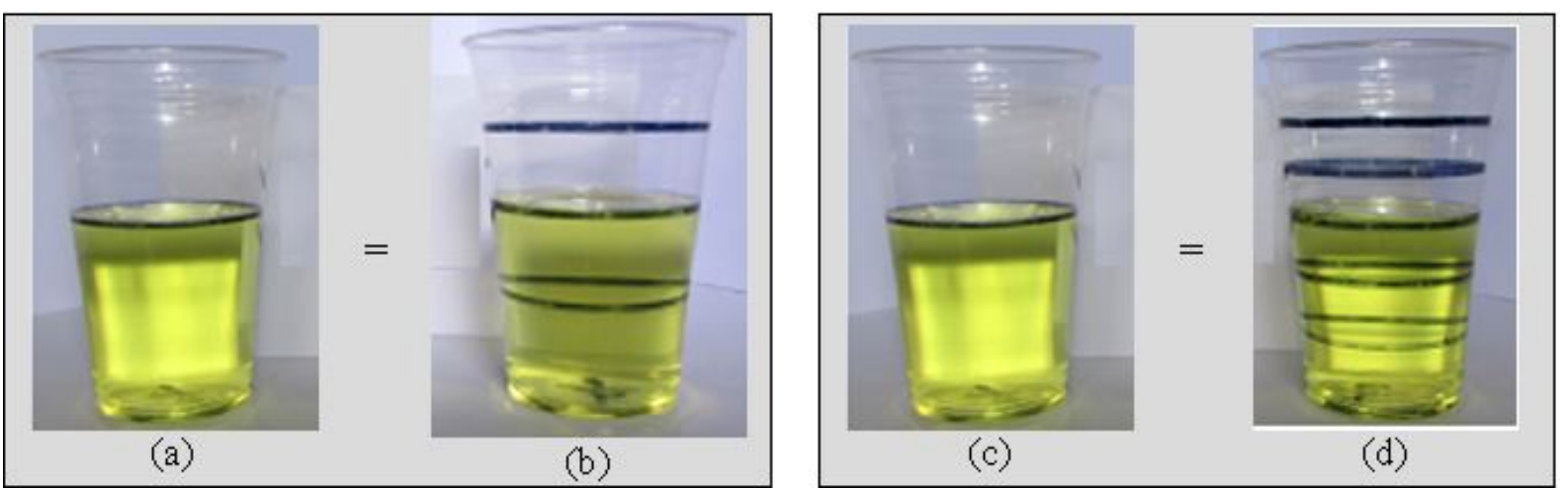

Fonte: Dados da pesquisa

Assim, infere-se que a quantidade do líquido contida no copo apresentado na Figura $5 a$ é a mesma contida no copo da Figura $5 b$, concluindo-se assim que, a fração $\frac{1}{2}$ é equivalente a $\frac{2}{4}$ e, esta é, por sua vez, equivalente a $\frac{3}{6}$. Logo, por transitividade, $\frac{1}{2}$ é também equivalente a $\frac{3}{6}$, como mostrado nas Figuras $5 c$ e $5 \mathrm{~d}$. Assim, diz-se que as três frações indicam a mesma quantidade, favorecida pela instrumentalização na relação do sujeito (S) pesquisador com o objeto Fração por mediação do instrumento (Copos com Fração). Por definição, as frações equivalentes são aquelas que têm a mesma quantidade de água nos copos. De outro modo, multiplicando o numerador e o denominador da fração $\frac{1}{2}$ por 2 (ou 3) obtém-se $\frac{2}{4}$ (ou $\frac{3}{6}$ ), que é uma fração equivalente a primeira (cf. Figuras $5 c$ e $5 d$ ). De modo geral, um esquema que permite encontrar frações equivalentes a uma dada fração na relação usual (S-O) do modelo SAI, possibilita multiplicar (ou dividir) o numerador e o denominador desta fração por um mesmo número diferente zero. Assim, o que pode ser acrescentado a esse estudo é a noção de simplificação de uma fração, se ao invés de multiplicar a fração dada por um número não nulo for efetuada a operação de divisão por um número não nulo, obtendo-se assim outras frações equivalentes a primeira, e o instrumento Copo com Frações pode auxiliar as práticas efetivas de alunos na instituição correspondente. 
A terceira tarefa T3 que compõe a SD foi elaborada com o seguinte enunciado.

\begin{tabular}{|l|l|}
\hline \multicolumn{2}{|l|}{ T3) Utilizar os Copos com frações e água colorida para realizar as seguintes } \\
subtarefas: \\
\hline St1 & Realizar a adição de $\frac{3}{5}$ com a fração $\frac{1}{5}$, isto é a operação $\frac{3}{5}+\frac{1}{5}$. \\
\hline St2 & Realizar a subtração de $\frac{3}{5}$ pela fração $\frac{1}{5}$, isto é a operação $\frac{3}{5}-\frac{1}{5}$ \\
\hline
\end{tabular}

Objetivo: Desenvolver as noções de adição e subtração de frações com denominadores iguais, utilizando Copos com Frações e água colorida, tendo como pré-requisitos, as operações de adição e subtração de frações com denominador iguais.

Análise Matemática: Para atender o objetivo da T3 realizou-se uma análise sequencial das duas subtarefas (St1, St2). Inicialmente observou-se que as frações fornecidas, tanto na St1 quanto na St2, têm o mesmo denominador, o cinco. Assim, os Copos com Frações devem ter a mesma quantidade de traços, ou marcas divisórias da capacidade total de cada copo. Neste caso, são exatamente quatro traços, sendo representantes da decomposição da referida capacidade em cinco partes. Com esse esquema, para efetuar a operação desejada basta juntar os conteúdos e observar a marcação atingida no copo. Neste contexto, mostra-se na Figura 6(a) um modelo ilustrativo da operação de adição de duas frações de mesmo denominador, representadas matematicamente por $\frac{3}{5}+\frac{1}{5}=\frac{4}{5}$.

Figura 6: Adição e subtração com frações.
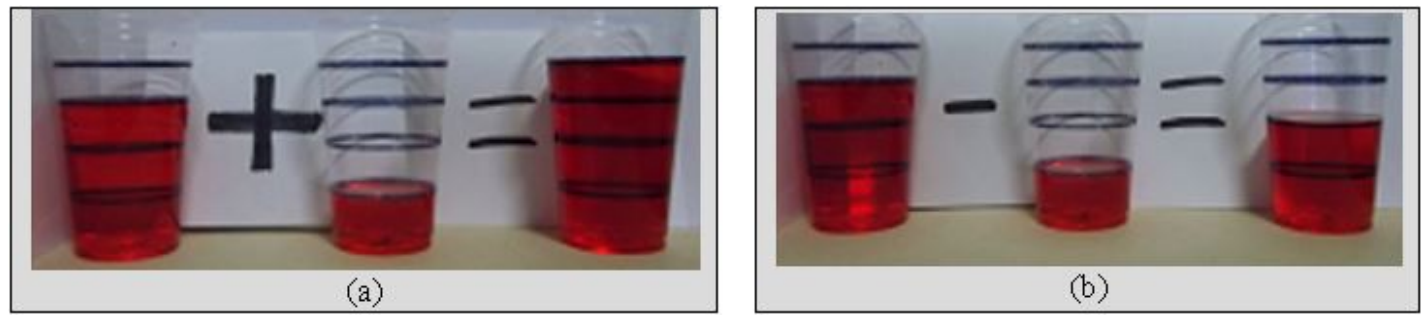

Fonte: Dados da pesquisa

O modelo ilustrativo da operação da subtração se diferencia da adição peculiarmente. Pois, ao invés de unir os conteúdos dos recipientes, retira-se a quantidade do conteúdo (água) referente ao valor a ser subtraído da fração desejada (fração maior). Analisando as duas situações observa-se que na Figura 6a houve um acréscimo na quantidade de água correspondente a fração representada por $\frac{1}{5}$. Enquanto no modelo apresentado na Figura $6 \mathrm{~b}$ houve uma redução da água em fração referente a $\frac{1}{5}$. Pode-se conjecturar que a visualização de Frações através de Copos com Frações pode auxiliar o aluno, enquanto sujeito na relação usual [S-O] com o objeto matemático Frações.

A quarta tarefa T4 foi elaborada com o seguinte enunciado. 
T4) Representar duas frações com denominadores diferentes, na folha de respostas, para realizar as seguintes subtarefas:

St1 $\quad$ Adicionar as frações representadas na folha.

St2 Subtrair as frações representadas na folha.

St3 Confeccionar os Copos com Fração utilizando as frações consideradas em T4.

St4 Determinar o m.m.c. entre os valores atribuídos aos denominadores e encontrar frações equivalentes às consideradas em T4. Confeccionar Copos com Fração utilizando estas frações equivalentes.

St5 Realizar a adição e subtração já efetuadas em St1 e St2 utilizando Copos com Fração.

Objetivo: Desenvolver noções de adição e subtração de frações representadas com denominadores diferentes, além de proporcionar aos alunos um momento de construção de seus próprios Copos com Frações, tendo como pré-requisitos as competências relacionadas à operação com adição e subtração de frações, determinação do mínimo múltiplo comum de dois ou mais números inteiros.

Análise Matemática: Para realizar a operação de adição ou subtração de frações com denominadores diferentes, respectivamente, foi relembrado aos alunos o conceito e a técnica para calcular o mínimo múltiplo comum (m.m.c) de dois números inteiros. No caso dos denominadores das frações este m.m.c representa a quantidade de partes de mesma capacidade em que o copo de referência para a resposta deve ser marcado com os traços. Nesta análise não são apresentados os resultados preliminares, pois estes provêm das ações e escolhas realizadas pelos alunos no momento da aplicação da SD. Porém, apresenta-se sutilmente aqui, alguns dos procedimentos possíveis de serem utilizados. Com relação a adição, deve-se juntar os conteúdos dos Copos com frações no copo correspondente que contém as marcações associadas ao m.m.c. dos denominadores. Para a subtração deve-se retirar o conteúdo do Copo com a Fração a ser subtraída.

\subsection{Aplicação, análise a posteriori e avaliação do jogo Copos com Frações}

No início da aplicação foi apresentada aos alunos a estrutura dos copos com os seus devidos traços, como divisórios da capacidade do copo (de $300 \mathrm{ml}$ ) em partes de medidas iguais. Também foi informado aos alunos o tipo de frações que poderiam ser representadas, uma vez que os traços nos copos sugerem os possíveis valores para os denominadores das frações que seriam trabalhadas. Por exemplo, o copo marcado com três traços poderia representar $\frac{1}{3}$ (um terço), $\frac{2}{3}$ (dois terços) e $\frac{3}{3}$ (três terços), fração que corresponde a um inteiro. O mesmo procedimento foi válido para os outros copos, considerando a quantidade de traços. Em seguida, os alunos foram organizados em grupos para a realização das tarefas com o auxílio do jogo. 
Na realização da primeira tarefa (T1) os alunos tiveram a oportunidade de revisitar a noção de fração viabilizando uma melhor compreensão dos conceitos de comparação de frações pela manipulação de objetos concretos, especificamente, com os Copos com Frações. Normalmente, na relação usual [S-O], dos alunos com este objeto (Fração), emergem dificuldades que se manifestam no desconhecimento de que a fração $\frac{3}{4}$ é maior que $\frac{2}{3}$. A superação mediada pelos Copos com Frações enquanto ferramenta, se tornou efetiva na medida em que a comparação da

quantidade de água exposta em cada copo foi considerada, viabilizando um enfrentamento dessa questão com algo prático. Nesse sentido, infere-se que os Copos com Frações funcionaram como instrumento efetivo, estimulando os alunos na comparação de frações sem a aplicação de técnicas formais. Durante o processo notou-se uma melhor familiarização dos alunos com os Copos com Frações, assim como com o tratamento de frações utilizando este instrumento. Com a realização das tarefas da SD pelos alunos percebeu-se que eles passaram a redescobrir a noção de frações equivalentes. Vale sublinhar que os alunos já tinham estudado frações equivalentes antes da aplicação da SD, cuja única referência ou recurso que tinham era o livro didático. A aplicação dessa sequência proporcionou o trabalho com frações de forma concreta, pela manipulação de quantidades equivalentes utilizando Copos com Frações. Vale ainda sublinhar que os alunos puderam perceber as frações distintas, indicando a mesma quantidade mobilizando representações equivalentes. Os cálculos propostos permitiram aos alunos perceberem que é possível obter quantidades iguais, mesmo quando as frações são diferentes. De fato, a quantidade de líquido em um copo, correspondente às frações envolvidas nas operações podia ser adicionada ou retirada com os divisórios iguais ao valor do m.m.c. de acordo com a operação visada, utilizando as frações equivalentes. A Figura 7 apresenta imagens do momento em que os alunos participavam da aplicação da SD utilizando, além dos Copos com Frações os seus respectivos cadernos para a realização das anotações.

Figura 7: Aplicação da atividade com os Copos com Frações.
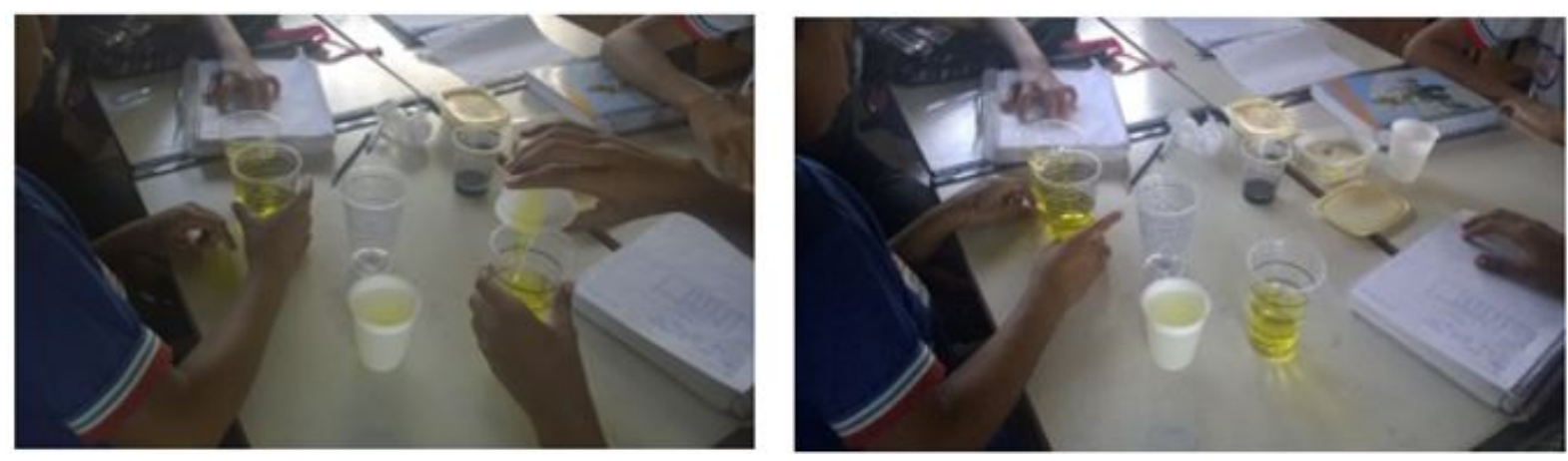

Fonte: Dados da pesquisa 
Os alunos podiam dialogar entre si durante a aplicação, o que transformou o espaço em um ambiente de desenvolvimento de esquemas de atividades coletivas instrumentadas, com a utilização conjunta de Copos com frações em um contexto de atividades compartilhadas, compartilhando, por conseguinte, os conhecimentos visados. Eles puderam, ainda, adicionar ou subtrair frações com denominadores diferentes transformando as frações por outras equivalentes a elas de mesmo denominador. No momento em que era efetuada a transformação, também ocorria a comparação e a confirmação de que se tratava de frações equivalentes, manifestando-se assim a gênese instrumental durante a utilização de Copos com Frações pelos alunos envolvidos na SD.

\section{CONCLUSÕES}

O uso planejado de materiais didáticos nas aulas de Matemática modifica a rotina da sala de aula e faz com o aluno mude a sua postura, assumindo um papel ativo na referida atividade, o que transforma a imagem negativa da Matemática e do professor de Matemática [14, 15]. Essa mudança no olhar sobre a Matemática, por parte dos alunos, contribui para quebrar uma barreira criada culturalmente e que faz um número considerável dos alunos acharem que o sucesso na disciplina de Matemática é reservada apenas a um grupo seleto de pessoas. Essa postura distancia as pessoas da Matemática, sendo um dos fatores responsáveis pelos baixos desempenhos de alunos de todos os níveis escolares nessa disciplina.

O conteúdo Frações não era, para os alunos da turma em que o PIBID-Mat realizou as suas atividades, algo desconhecido, porém faltava estratégias que permitissem favorecer a relação entre o conteúdo proposto no ensino deste objeto com situações capazes de fazer com que eles compreendessem a estrutura de uma fração, justificando a forma com a qual os cálculos são realizados nas operações.

$\mathrm{O}$ artefato confeccionado foi muito bem aceito pelos alunos que se mostraram entusiasmados no dia da sua aplicação. Essa reação já era esperada, uma vez que a atividade foi planejada para modificar a rotina dos alunos na escola, sendo essa uma característica das atividades que envolvem jogos educacionais. Ao apontarem o tópico Frações como objeto matemático de referência para a intervenção, os Professores supervisores das escolas envolvidas esperavam, em tempo curto uma ação e apoio por parte da Universidade, na tentativa de amenizar as dificuldades dos seus alunos na aprendizagem de Frações.

A Abordagem Instrumental forneceu subsídios para a constituição do jogo Copos com Frações como instrumento para a aprendizagem. O processo de gênese instrumental apreciado permitiu que as potencialidades do artefato fossem reconhecidas e aprimoradas, a partir da instrumentação e instrumentalização. 
Vale ressaltar a atuação dos licenciandos, bolsistas de Iniciação à Docência. Com a realização desse subprojeto os bolsistas tiveram a oportunidade de vivenciar o dia a dia da escola, de problematizar situações didáticas vivenciadas na sala de aula de Matemática e de refletir criticamente sobre elas, a partir de um olhar teórico. O trabalho conjunto com as supervisoras, possibilitaram o compartilhamento de conhecimentos e momentos de formação baseado na prática do uso de metodologias.

Por fim, a aplicação e análise da Sequência Didática apresentada permitiu concluir que a revisitação de conceitos de Frações numéricas, já trabalhos em aulas tradicionais, utilizando o jogo Copos com Frações viabiliza a transformação do conhecimento matemático, oferecendo maior visibilidade, comparação e apropriação dos conceitos correspondentes pelos alunos.

\section{REFERÊNCIAS}

[1] R. Fiscarelli, Material Didático: discursos e saberes, Junqueira \& Marin, Araraquara, 2008.

[2] P. H. B. Thomaz, M.A.B.A. Megid, Recursos didáticos no ensino da Matemática: o jogo como estratégia de ensino e o programa ler e escrever. Currículo sem fronteiras, 17 (2017), pp. 833 847.

[3] K. R. Jelinek, Jogos nas aulas de Matemática: brincadeira ou aprendizagem? O que pensam os professores?, Dissertação de Mestrado em Ciências e Matemática - Faculdade em Física, Pontifícia Universidade Católica do Rio Grande do Sul, 2005.

[4] J. L.S. Silva, J. R. Evangelista, R. B. Santos, P. M. Mendes, Matemática Lúdica: Ensino fundamental e médio. Educação em Foco, 5 (2013), pp. 26 - 36.

[5] D. Fiorentini, F. C. Castro. Tornando-se professor de Matemática: o caso de Allan em Prática de ensino e Estágio Supervisionado. In: D. Fiorentini (org.). Formação de professores de Matemática: explorando novos caminhos com outros olhares. Campinas: Mercado de letras, 2003. Pp 53-85.

[6] M. C. Borba, H. R. F. L. Almeida, T. A. S. Gracias, Pesquisa em ensino e sala de aula: diferentes vozes em uma investigação, Autêntica, Belo Horizonte, 2018.

[7] P. Freire, Extensão ou comunicação? 19º ed. Paz e Terra, São Paulo, 2018.

[8] P. Rabardel, Les hommes et les technologies: une approche cognitive des instruments contemporains. Paris: Armand Colin, 1995.

[9] A. Henriques, Um estudo de superfícies e de integrais múltiplas em ambiente computacional. In: Anais do VIII Encontro Nacional de Educação Matemática, UFPE, Recife, 2004, pp. 1-16.

[10] A. Henriques, J. P. Attie, L. M. S. Farias, Referências teóricas da didática francesa: análise didática visando o estudo das integrais múltiplas com auxílio do software Maple. Educação Matemática Pesquisa, 9, (2007), pp. 51-81.

[11] A. Henriques, Análise Institucional \& Sequência Didática como Metodologia de Pesquisa. In: Anais do I Simpósio Latino-Americano de Didática da Matemática, Bonito, Sistema Tuse, 2016, pp. 1-16.

[12] A. Henriques, Reflexões sobre análises institucionais e sequências didáticas: o caso do estudo de integrais múltiplas. Progressão de Carreira do Magistério Superior, de Adjunto a Titular. Universidade Estadual de Santa Cruz. Ilhéus, Bahia, Brasil, https://sites.google.com/site/gpemac/ dissertacoes-de-mestrado. 2011 (acessado em 14 de agosto de 2020). 
[13] A. Henriques, Estudo de relações em sala de aula com a presença de ambientes computacionais de aprendizagem - PERSAC. In: Anais do III Seminário Regional do LIAPEME \& I Colóquio Internacional Sobre Ensino e Didática das Ciências, UEFS, Feira de Santana, 2014, pp. 68-78.

[14] M. C. Borba, R. S. R. Silva, G. Gadanidis, Fases das tecnologias digitais em Educação Matemática: sala de aula e internet em movimento. 2. ed., Autêntica, Belo Horizonte, 2018.

[15] R. R. S. Scucuglia, Narrativas multimodais: a imagem dos matemáticos em performances matemáticas digitais. Bolema, v. 28, n. 49, 2014, pp. 950-973. [CrossRef]

\section{BREVE BIOGRAFIA}

Liliane Xavier Neves (D) https://orcid.org/0000-0001-8535-0779

Doutora em Educação Matemática pela Universidade Estadual Paulista "Júlio de Mesquita Filho". Professora Assistente da Universidade Estadual de Santa Cruz. Integrante do Grupo de Pesquisa em Ensino e Aprendizagem da Matemática em Ambiente Computacional (GPEMAC), do Grupo de Pesquisa em Informática, outras Mídias e Educação Matemática (GPIMEM) e do Grupo de Articulação, Investigação e Pesquisa em Educação Matemática (GAIPEM).

Rosane Leite Funato (D) https://orcid.org/0000-0002-6799-0876

Mestre em Matemática pela Universidade Federal da Bahia (2005). Professora assistente da Universidade Estadual de Santa Cruz, coordenadora do Pibid subprojeto Matemática e Integrante do Grupo de Pesquisa em Ensino e Aprendizagem da Matemática em Ambiente Computacional - GPEMAC.

Afonso Henriques (D) https://orcid.org/0000-0002-8783-6008

Doutor em Matemática e Informática pela Universidade Joseph Fourier Grenoble - França (2006), revalidado no Brasil pela Universidade Federal de Pernambuco UFPE (2010). Professor Pleno na Universidade Estadual de Santa Cruz. Coordenador do Grupo de Pesquisa em Ensino e Aprendizagem da Matemática em Ambiente Computacional (GPEMAC) e do Laboratório de Visualização Matemática (L@VIM) da UESC. 